\title{
Navigation and robot-aided surgery in the spine: historical review and state of the art
}

\author{
This article was published in the following Dove Press journal: \\ Robotic Surgery: Research and Reviews \\ 16 September 2014 \\ Number of times this article has been viewed
}

\author{
Amr Nimer Amr \\ Alf Giese \\ Sven R Kantelhardt \\ Department of Neurosurgery, \\ University Medical Center, Johannes \\ Gutenberg University of Mainz, \\ Mainz, Germany
}

Correspondence: Sven R Kantelhardt Department of Neurosurgery, University Medical Center, Johannes Gutenberg University of Mainz, I Langenbeckstrasse, Mainz 55I3I, Germany

Tel +49 6I3I I77 33I

Fax +49 6I3 I I747 3734

Email sven.kantelhardt@unimedizinmainz.de

\begin{abstract}
Spinal anatomy is complex and in close vicinity of vulnerable anatomical structures, such as nerve roots, spinal cord, and blood vessels, requiring high precision in surgical procedures, while the surgical exposure is limited and even more limited in percutaneous procedures. A high risk of misplaced implants and/or high intraoperative radiation exposure are the consequences. Spinal navigation techniques have been introduced to alleviate these problems. The majority of reports on navigation document its role in increasing implant-placement accuracy and reducing intraoperative radiation. The technology is increasingly finding acceptance amongst spinal surgeons. This however does not yet present the end of the road. Robotic applications could be regarded as a coherent continuation of spinal navigation. We reviewed the literature pertaining to spinal navigation, as well as novel and upcoming robotic applications for spinal surgery. For this purpose, a Medline search using the terms "robot" and "spine" and extensive cross-reference analysis (using Medline, Ovid, and Web of Science data banks) were performed. The goal was to provide an overview of present achievements and novel developments in this fast-growing research area. While a number of robotic techniques are under investigation, mainly to aid navigated screw placement, the SpineAssist/Renaissance system has cleared US Food and Drug Administration approval and is in relatively wide clinical use. Another robotic system, the da Vinci, is currently applied in an increasing number of cases under research protocols.
\end{abstract}

Keywords: robotics, navigation, spinal surgery, instrumentation, image-guided surgery, pedicle screw

\section{Introduction}

The challenges facing the spinal surgeon are manifold, the foremost of which is the inherent lack of direct visibility of the relevant anatomical structures. This may in turn lead to a multitude of complications, such as diminished precision in the case of implants with ensuing neurological complications, ${ }^{1}$ as well as the necessary but significant surgical trauma in the case of "open" procedures, with all the complications that such procedures may entail. Further challenges include substantial exposure to radiation while utilizing intraoperative radiological technology, and the often-neglected but increasingly critical socioeconomic challenges. ${ }^{2}$ Progress in the field of imageguided and computational neuronavigation in the spine has considerably reduced the rate of misplaced implants in spinal instrumentation procedures ${ }^{3}$ and radiation exposure to the surgeon, the patient, and the operating theater staff. Furthermore, they allow the application of minimally invasive approaches without elevating the risk of implant misplacements, and can thus help to decrease skeletomuscular surgical trauma and ultimately the length of the hospital stay of patients. ${ }^{4}$ In this article, we trace the 
progress of spinal navigation and image guidance toward robotic surgery, which can be regarded as a coherent continuation of this development. Furthermore, we give an overview over robotic technologies currently under investigation in spinal surgery.

\section{Materials and methods}

In order to identify the historical development, recent achievements, and upcoming technologies for robot-aided spine surgery, we performed a Medline search using the terms "robot" and "spine". All resulting matches (129) were analyzed. Papers that were found to deal with spinal robotics were than categorized in terms of whether they were experimental (technical papers and/or cadaver experiments), case reports, or clinical studies. Following this, an extensive cross-reference analysis (using Medline, Ovid, and Web of Science databanks) was performed.

In addition, articles documenting the development of navigation technologies were selected with regard to their contribution toward spinal robotics. This part of the review does not however claim to include all articles on spinal navigation, as they are far too numerous for this kind of review. In our institution, no formal approval of the corresponding ethical committee was required.

\section{Historical perspective}

The treatment of spinal disorders is by no means a modern phenomenon. Before the advent of the X-ray era in 1895, the therapy ranged from the supernatural in antiquity to the bizarre and barbaric in the period leading to the early nineteenth century. ${ }^{5,6}$ In the period between the development of the Lister method in 1867, which enabled surgeons to cut the rates of infection dramatically (leading to a remarkable increase in the number of surgeries performed) and 1925, when the first diagnostic use of X-rays in spinal surgery was executed, surgeons depended on a profound knowledge of the spinal anatomy to locate the spinal lesions in question. Dandy introduced pneumomyelography in 1919, a procedure that is regarded as a milestone in both spinal surgery and radiology, a method that remained in use for many decades.

It was not until Hounsfield developed computed tomography (CT) in 1971 and the invention of magnetic resonance imaging (MRI) in the 1980s that the rapid progress in spinal imaging ensued. It was then possible to obtain relatively high-resolution images of the spine, enabling both a more precise diagnosis as well as surgical planning. The evolution of spinal imaging continues to this day, with the introduction of various devices for intraoperative imaging, including the conventional C-arms with 3-D imaging function (Figure 1), intraoperative $\mathrm{CT}$, and MRI: devices that enable real-time 3-D rendering of spinal anatomy.

Another approach to minimize the risk of intraoperative deviations from the surgical plan is the application of imageguidance or navigation techniques. Navigation in neurosurgical operations is the child of stereotaxy. ${ }^{7}$ In conventional stereotaxy, a reference frame is fixed to the patient's head and examined together with the target volume (the head) by CT or MRI. Because the reference system is included in the imaging study, the optimal trajectory leading to the target can be calculated in relation to the reference frame. This technique was first reported by Roberts et al in 1986, paving the way for wide-ranging developments in the field of navigation. ${ }^{8}$

\section{Problems facing the spinal surgeon}

The problems facing the surgeon in complex spinal procedures include poor visibility of the anatomical structures in question, especially in the case of spinal implants, where precision may suffer due to the lack of visibility. The complex anatomy of the spine and the relative proximity to vital anatomical structures, such as nerves and vessels, render the accuracy of screw placement a major concern in spine surgery. A systemic review overlooking 26 prospective clinical studies of pedicle-screw placement by Gelalis et $\mathrm{al}^{9}$ showed a wide variance of precision of pedicle placement in freehand procedures, ranging from $69 \%$ to $94 \%$, while the accuracy with the aid of fluoroscopy ranged from a paltry $28 \%$ to $85 \%$. In percutaneous procedures, deviation rates tend to be

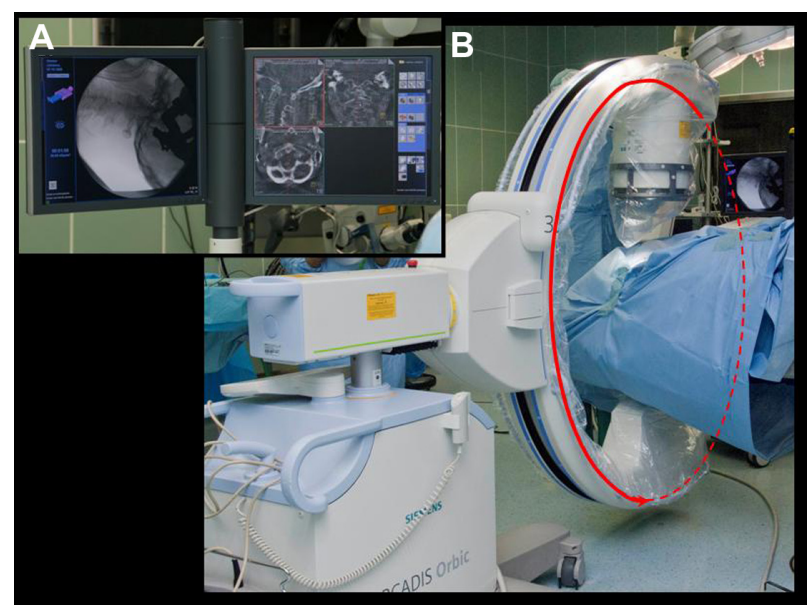

Figure I (A and B) C-arm used for intraoperative 3-D imaging and navigation (Arcadis Orbic; Siemens, Munich, Germany).

Notes: (A) The screen displays conventional fluoroscopy images on the left and 3-D reconstruction on the right. (B) System setup. The C-arm is covered by a sterile drape and rotates around the patient to perform 3-D scanning (the C-arm's automated movement is illustrated by the red circular line). 
even higher (between $20 \%$ and $93.4 \%{ }^{10-12}$ ), which is easily explained, as the surgical exposure and visibility of anatomic landmarks is further reduced.

Another major issue facing the spinal surgeon - and the patient - is the amount of radiation exposure before, during, and after the operation. The pre- and to some extent postoperative CT imaging, while exposing the patient to a significant amount of radiation, are of vital importance, and hence cannot be eliminated. Intraoperative radiation does in addition expose the surgeon and the surgical team, who in contrast to the patient face this during their daily work. Corresponding to the rate of misplaced implants, the application of percutaneous techniques tends to increase intraoperative radiation exposure. ${ }^{13}$

\section{Navigation}

Frameless stereotaxy (also termed navigation, neuronavigation, or image guidance) has overshadowed its frame-based predecessor. It is however based on the same principles. ${ }^{14}$ The reference frame is replaced by a reference-marker array, which is likewise fixed to the patient. Its spatial position in relation to the target volume is than determined by either imaging studies (2-D or 3-D fluoroscopy), mirroring the process in conventional stereotaxy. Alternatively, a pointer or laser beam is directed to surface points on the object of interest (patient's head, spine, etc). Registration is then conducted by determining the spatial relationship between the applied preoperative imaging study's space-coordinate system and the physical space coordinates of the object of interest by matching the acquired surface points to a virtual 3-D model of the object of interest. ${ }^{15}$

There are various methods to navigate the spine and to reference and register the images with the spinal anatomy. Unlike cranial navigation, spinal navigation suffers from a major obstacle, namely spinal anatomical mobility. This is especially problematic if navigation is based on preoperative imaging studies, which are mostly performed in the supine position, while most surgical approaches are performed in prone position. To register and reference a patient, each segment either has to be segmented in the preoperative imaging study and then registered separately, ${ }^{4}$ or the imaging study has to be performed after final positioning of the patient. ${ }^{16}$ Broadly speaking, one can divide the referencing methods into four categories: 1) 2-D fluoroscopybased navigation, ${ }^{17}$ 2) 3-D fluoroscopy-based navigation (Figure 1), ${ }^{16-19} 3$ ) preoperative CT/MRI-based navigation (Figures 2 and 3), ${ }^{4,20}$ or 4 ) intraoperative CT/MRI-based navigation. ${ }^{17,21-23}$

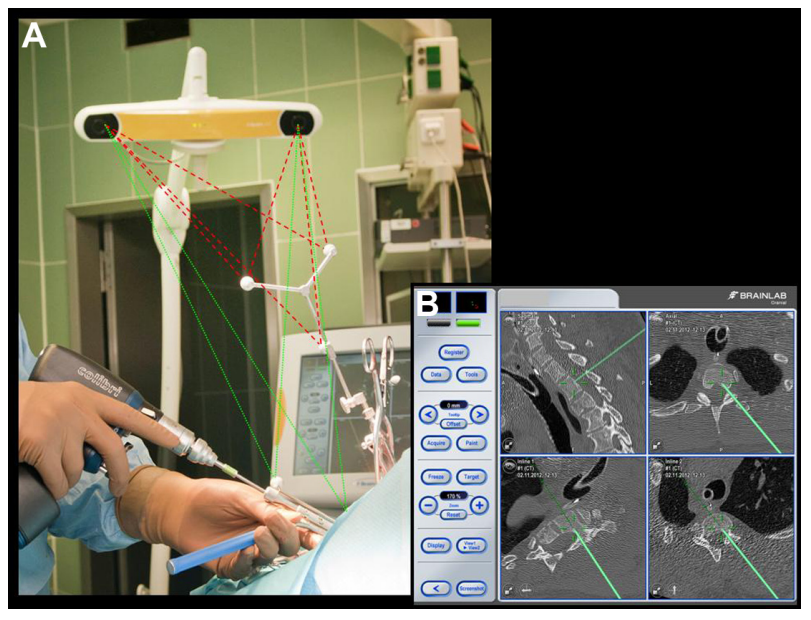

Figure 2 (A and B) Conventional navigation system (Kolibri; Brainlab, Feldkirchen, Germany).

Notes: (A) Intraoperative setup, featuring a stereo camera, which simultaneously tracks the reference-marker array (red lines) and a registered drill guide (green lines). (B) The navigation-system screen displays the current position of a tracked instrument on sagittal, axial, and in-line view reconstructions of the preoperative computed tomography.

Navigation-based techniques have been shown to increase the accuracy rate in pedicle-screw placement, ${ }^{24,25}$ even in the case of pediatric spine surgery. ${ }^{26}$ In the review cited earlier, Gelalis et $\mathrm{al}^{9}$ found that CT- and fluoroscopy-based navigation increased the accuracy rate of implants to $89 \%-100 \%$ and $89 \%-92 \%$, respectively. Tian et al found likewise in their review summarizing 43 studies a significantly increased accuracy rate of navigated pedicle screws. ${ }^{27}$ In contrast to Gelalis et al, they found 3-D fluoroscopy-based navigation to be slightly more accurate than CT or 2-D fluoroscopy-based navigation, ${ }^{27}$ while Mason et al found 3-D fluoroscopybased navigation to be significantly more accurate than 2-D fluoroscopy-based navigation or conventional fluoroscopy. ${ }^{28}$ Studies furthermore showed that the application of navigation

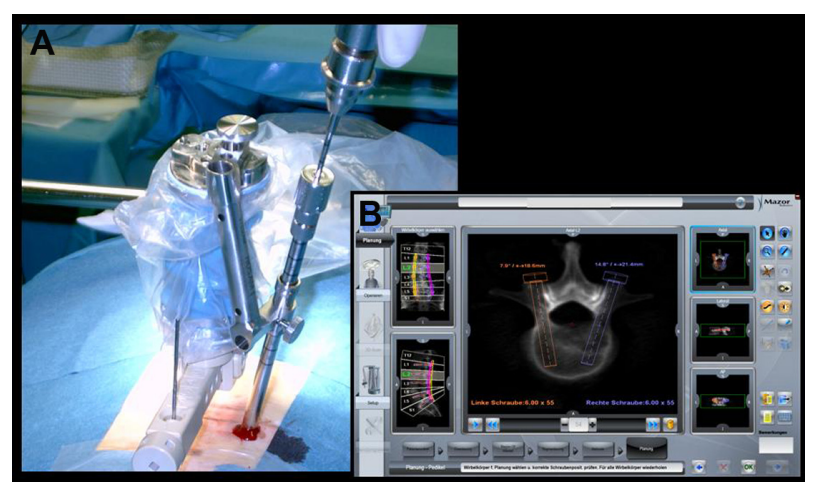

Figure 3 (A and B) Intraoperative setup of the Renaissance miniature robot (Mazor Robotics, Caesarea, Israel).

Notes: The robot is mounted on a clamp fixed to a spinous process. It is currently holding the drill guide (A) according to the operative plan that is based on the preoperative computed tomography (B). 
can also increase the accuracy rate in percutaneous procedures, ${ }^{4,29}$ while other studies showed that the application of different navigation technologies can reduce intraoperative radiation exposure even in percutaneous cases. ${ }^{13,30}$ It has however to be noted that none of the large meta-analyses could consistently show a clinical benefit of the application of navigation. This is not as surprising as it might appear at first sight. Many clinicians accept screw deviations up to 2 or $3 \mathrm{~mm}$ because they are rarely symptomatic. Lonstein et al, for example, report in a meta-analysis on 4,790 screws of $0.2 \%$ neurological complications in $5.1 \%$ pedicle perforations. ${ }^{31}$ These numbers demonstrate what a huge patient collective would be required to prove a real clinical benefit (significant reduction of neurological deficits), which the rather marginal improvement of screw-positioning accuracy might effect. In large meta-analyses that overlook sufficient numbers of screws in contrast, the clinical data are often too heterogeneous to draw coherent conclusions.

Today, navigation is nevertheless routinely used by spine surgeons worldwide, though its acceptance differs from surgeon to surgeon. An international survey by Härtl et al of 677 spinal surgeons in five international geographical regions showed varying degrees of acceptance and use of socalled computer-assisted surgery, ${ }^{32}$ with some surgeons using navigation frequently, others only for selected cases, and a last group that saw no benefit in the application of navigation technologies and did not implement it. This seemed to correlate with the amount of spinal procedures performed: surgeons performing frequent procedures were more accepting of navigation and performed spinal procedures with navigation more often. ${ }^{32}$

\section{Robotic spine surgery}

The case for using spinal robotics is compelling: when used correctly, the application of robots increases the accuracy of implant placement (as shown by Kantelhardt et al, ${ }^{4}$ Devito et al, $^{33}$ and Schatlo et $\mathrm{al}^{34}$ ), it lessens the time of and exposure to radiation, and allows a more minimally invasive technique, resulting in shorter convalescence periods, less musculoskeletal trauma, and thus a lower risk of infections and other complications. ${ }^{35}$ Robots appear to be ideal surgical assistants in spinal surgery due to their inherent characteristics: the ability to perform tasks repeatedly without fatigue or loss in accuracy, the ability to lesson or eliminate hand tremors, ${ }^{35}$ and the ability to accurately guide the surgeon to the target with high precision.

While navigation in spinal surgery has been available for almost two decades, robot-assisted spinal surgery - indeed, robotic surgery itself - is a relatively newer phenomenon, ${ }^{36}$ with consequently less widespread use than conventional navigation. While robotic applications in surgical procedures found acceptance and relatively widespread use in other disciplines, such as urology and general surgery, robotics in spinal surgery remains a relatively newer development. We have found no reliable data on how widespread the use of robots is in spinal procedures in a Medline search of the English and German languages.

\section{Experimental systems}

Most systems presently discussed in the literature are still experimental, and have been applied on models or human cadavers. ${ }^{37-40}$ Some robots have been applied in limited series of cases under a research protocol. ${ }^{37}$ The only exceptions are the SpineAssist ${ }^{\mathbb{}} /$ Renaissance $^{\mathrm{TM}}$ system of Mazor Robotics (Caeserea, Israel) and the da Vinci robotic surgical system (Intuitive Surgical, Sunnyvale, CA, USA), which will be described in a separate section.

Most of the experimental systems are thought to guide surgeons during pedicle-screw ${ }^{37}$ or transarticular $\mathrm{C} 1 / \mathrm{C} 2$ screw placement. ${ }^{38}$ The Miro system was developed and investigated in the German Aerospace Center. One of the applications considered was pedicle-screw placement. The system consisted of a lightweight robot, holding a drill guide, a control, and an optical tracking system. ${ }^{40} \mathrm{Kim}$ et al developed the biplane fluoroscopy-guided robot system, which combines imaging using an $\mathrm{O}$-arm with an operating system and robot arm (Spinebot). After imaging and registration by the Spinebot, the system's software is used for planning of screw trajectories, and finally the Spinebot robot arm positions a guiding tube on the planned trajectory. The system was successfully tested in 28 pedicles of two cadaveric specimens. ${ }^{39}$ Kostrezewski et al developed a robotic system for screw placement in the cervical and possibly other segments of the spine. After positioning of the robot over the field of interest by the surgeon (in a suspension frame), an optical tracking system like those used in conventional navigation is applied to move the robot drill guide into the preplanned position. The system was tested by placing transarticular $\mathrm{C} 1 / \mathrm{C} 2$ screws in six cadaveric spine specimens. ${ }^{38}$ The Spine Bull's-Eye Robot is a remote-controlled instrument, which places guiding wires under pedicle-axis standard-view fluoroscopy. It consists of a robot arm and base, a console, a remote-control system, a $\mathrm{C}$-arm, and a radiolucent manipulator. It was successfully tested in 203 cadaveric pedicles and three patients (seven pedicles). ${ }^{37}$

Other robotic applications in the spine include robotic assisted radio-surgery using the CyberKnife ${ }^{\circledR},{ }^{41}$ a force-controlled robot for assisted drilling of the 
laminae, ${ }^{42}$ experimental injections using a robot arm guiding a flat-panel detector CT and electromagnetic navigation, ${ }^{43}$ or remote-controlled injector for CT-guided punctures. ${ }^{44}$ A further application of robotics is the biomechanical testing of spinal specimen and implants ${ }^{35,45,46}$ or the support of physiotherapy training during rehabilitation from spinal injuries and surgery. ${ }^{47}$

\section{Systems in clinical practice SpineAssist/Renaissance}

A review by Bertelsen et al showed no fewer than 18 spinal robots, yet there existed only five commercially available systems and only one that was approved for spinal surgery: ${ }^{48}$ the Renaissance system and its predecessor SpineAssist. The Renaissance and SpineAssist systems constitute a miniature can-size mounted robot attached to either a bony structure on the patient's spine, a fixed bed mount, or a mounting platform fixed by pins to the patient's spine. ${ }^{49,50}$ The patient is registered by matching intraoperative fluoroscopy images to a preoperative CT scan on which the individual vertebrae have previously been segmented. The preoperative planning performed on the patient's spinal CT scans using the provided software also delivers the needed data for pedicle-screw placement. The robot swings and rotates to the desired area, providing a guided trajectory for drilling the pedicles and placement of a guiding wire and finally the pedicle screws (Figure 3). As in most experimental systems discussed earlier, the SpineAssist/ Renaissance system merely provides a pathway or guidance for screw placement; the actual placement itself is performed by the surgeon. Therefore, there is no loss of tactile control, and the screw positioning is continually controlled by the surgeon. Besides pedicle-screw placement, the system can be used to guide other spinal procedures, as long as they follow a single trajectory. It is used in the thoracic, lumbar, and sacral spine, although its application in individual cervical cases has been reported. ${ }^{51}$ The SpineAssist has been used for placement of implants besides pedicle screws (translaminar facet screws), ${ }^{52,53}$ spinal needle biopsies, and kyphoplasty. ${ }^{54}$ Furthermore, the recent version of the Renaissance system features a software suite that allows 3-D reconstruction of images taken with a conventional $\mathrm{C}$-arm, ${ }^{55}$ thereby providing intraoperative control of implant placement with universally available standard hardware.

There have been several retrospective series and a few prospective studies in the past years that evaluated the use of the SpineAssist, and fewer for the relatively new Renaissance system (Table 1). The majority of these studies showed that the accuracy of screw placement is increased with the robotic system, while at the same time decreasing radiation exposure. ${ }^{433,56-59}$ Only one study demonstrated a decrease in accuracy when using the SpineAssist in comparison to fluoroscopy guidance. ${ }^{60}$ There are no reliable data to date about the improvement in neurological or clinical outcomes in patients operated upon with the spinal robot.

\section{da Vinci}

The da Vinci robotic system has been routinely used in a number of surgical disciplines, most notably urology and gynecology, with over 200,000 procedures performed worldwide in 2012 alone. The da Vinci system relies on a surgical console to control the robotic arms and a patient cart that holds the arms. These arms can be used to hold various surgical instruments, or alternatively to be controlled by the surgeon to perform certain movements. da Vinci users have reported a reduction in hand tremors, greater precision, and the ability to perform less invasive procedures.

The da Vinci is a typical master-slave system. The surgeon is seated at a console looking at a screen and manipulates two two-finger-controlled handles. The movements of the surgeon (the "master") are transmitted to the

Table I Summary of clinical studies on the SpineAssist/Renaissance system

\begin{tabular}{|c|c|c|c|c|c|c|c|}
\hline Study & $\begin{array}{l}\text { FH } \\
\text { screws } \\
\text { (n) }\end{array}$ & $\begin{array}{l}\text { RG } \\
\text { screws } \\
\text { (n) }\end{array}$ & $\begin{array}{l}\text { FH } \\
\text { accuracy } \\
(\%)\end{array}$ & $\begin{array}{l}\text { RG } \\
\text { accuracy } \\
(\%)\end{array}$ & $\begin{array}{l}\text { FH X-ray } \\
\text { time (s) }\end{array}$ & $\begin{array}{l}\text { RG X-ray } \\
\text { time (s) }\end{array}$ & Comments \\
\hline Devito et $\mathrm{al}^{33}$ & - & 3,912 & - & 98.3 & - & & Accuracy based on Gertzbein and Robbins criteria \\
\hline Hu et $\mathrm{al}^{56}$ & - & 960 & - & 98.9 & - & - & Own grading criteria \\
\hline Kantelhardt et $\mathrm{al}^{4}$ & 286 & 250 & 96.5 & 98.9 & 77 & 34 & Own grading criteria \\
\hline Pechlivanis et $\mathrm{al}^{58}$ & - & 122 & - & 98.5 & - & - & Accuracy based on Rampersaud criteria \\
\hline Ringel et $\mathrm{al}^{60}$ & 152 & 146 & 93 & 85 & 114 & 114 & Accuracy based on Gertzbein and Robbins criteria \\
\hline Roser et $\mathrm{al}^{57}$ & 40 & 72 & 97.5 & 99 & 31.5 & 15.98 & Accuracy based on Gertzbein and Robbins criteria \\
\hline Schizas et $\mathrm{al}^{59}$ & 64 & 64 & 92.2 & 95.3 & 14.2 & 16.7 & $\begin{array}{l}\text { Accuracy based on Rampersaud criteria } \mathrm{A}+\mathrm{B} \text {, } \\
\text { (grade } \mathrm{A} \text { alone was higher in the } \mathrm{FH} \text { group) }\end{array}$ \\
\hline Sukovich et al ${ }^{67}$ & - & - & - & 93 & - & - & $\begin{array}{l}\text { Own grading criteria, } 49 \text { levels instrumented, } \\
\text { number of screws not indicated }\end{array}$ \\
\hline
\end{tabular}

Abbreviations: -, not assessed; FH, freehand; RG, robot-guided; s, seconds. 
three or more robot arms (the "slave") in real time. One of the arms controls an endoscope, while the other two can be used to manipulate several instruments. The movements can be downscaled at $1: 1,1: 3$, or 1:5, respectively, thereby eliminating tremors and unintended small movements. The robot arms allow $7^{\circ}$ of liberty, surpassing even the human hand. Although it is not US Food and Drug Administration (FDA)-approved for spinal procedures, the da Vinci robot has been increasingly applied in spinal procedures under research protocols in recent years. Yang et al tested the da Vinci system in a swine model, performing an anterior lumbar interbody fusion. ${ }^{61}$ Lee et al described an actual clinical laparoscopic anterior lumbar interbody fusion using the da Vinci robot with no complications. ${ }^{62}$ Yang et al reported on the use of the da Vinci in the resection of a lumbar paraspinal schwannoma ${ }^{63}$ while Perez-Cruet et al reported on a resection of a large spinal schwannoma with intrathoracic extension. ${ }^{64}$ Both groups reported no significant complications. Another group (Lee et al) reported two transoral robotic surgeries - to the craniocervical junction and odontoidectomy - in cadaveric studies using the da Vinci system. ${ }^{65,66}$ These reports prove the feasibility of the da Vinci system in complex spinal surgery, yet more clinical studies and larger patient series are needed before an FDA approval and widespread use of the system in spinal surgery can take place.

The type of cases where da Vinci-assisted surgery was considered demonstrate that the system is applied in a very different fashion than the SpineAssist/Renaissance or most of the experimental systems described earlier. While the latter provides navigation information and physical guidance to find preselected trajectories (for screw placement, etc), the da Vinci is designed for downscaling the surgeon's movements, assisting during tissue dissection, tumor removal, and related tasks, and does not provide any navigation information.

\section{Limitations of this review and the development of medical robotics in general}

This review is focused on technical and clinical achievements, and upcoming novel technologies in spinal robotics. However, for final acceptance of robotic technologies in spinal surgery, social, ethical, and of course financial issues have to be considered.

The imbalance between purely technical papers reporting on novel concepts and possibly cadaver experiments and clinical data reflects this problem. Surgery is a dangerous procedure, and surgeons are well advised to regard novel developments with some caution. To convince surgeons to change a well-established technique and try novel technologies, the expected benefit has to clearly outmatch the efforts, especially in terms of patient safety. As discussed earlier, the benefits of spinal robotics are rather gradual. The average implant precision may be elevated, especially in percutaneous procedures. However, depending on the surgeon's experience and abilities, the same results can in principle be achieved without the application of robotics.

If this is true for surgeons who have a deeper understanding of the relevant facts, potential patients are even more strongly influenced by nontechnical factors. Sociocultural issues affect the acceptance of robotics. In Germany, for example, problems that the national press attributed to the application of the Robodoc ${ }^{\circledR}$ system (Integrated Surgical Systems, Davis, CA, USA) in total-hip arthroplasty in the 1990s still affect the public perception of medical robotics.

A further factor is the cost of the application of novel (robotic) technologies. The SpineAssist/Renaissance system, for example, is approved by the FDA and a number of national administrations (including all EU countries, Israel, Russia, South Korea). In none of these countries, however, insurance companies or other health care providers cover the additional costs for acquisition of the system and onetime materials. Therefore, reimbursement for the technology is based on the gain in the hospital's reputation and consequently better patient acquisition, the reduced rate of misplaced implants and consecutive revision surgeries, and the potential financial benefit of shortened hospitalization and reduced medication costs if procedures are performed percutaneously, which otherwise might be performed via conventional incision. ${ }^{4}$ This situation reflects that of the da Vinci robot in urology. Some departments therefore raise an additional fee if patients want "robotic surgery", which the patient has to pay himself or to cover with a specialized insurance contract. This, however, paves the way toward an (undesirable) two-class medical system, in which only wealthy patients would gain from such technical developments as robotic spine surgery.

\section{Conclusion and future perspectives}

We reviewed navigation techniques and robot-aided surgical systems for spinal surgery. The majority of studies performed on spinal navigation show that the application of navigation technology may decrease implant misplacement and intraoperative radiation exposure, while no study has yet shown a clear clinical benefit if navigation technologies were applied. Navigation technologies are nevertheless increasingly finding acceptance among spinal surgeons, yet several concepts and systems compete, and few reviews, like Tian et al or Gelalis et al, have been undertaken to compare different 
navigation technologies among one another. ${ }^{9,27}$ Robotic spine surgery has recently been developed as a continuation of spinal navigation. Most robotic systems are designed to guide surgeons during screw placement, and have been tested in cadaveric studies or under research protocols. The SpineAssist/Renaissance is currently the only FDA-approved robotic spinal surgery system, and is relatively widely used in clinical practice around the world. The majority of studies investigating this system show a greater precision in implant placement, a decrease in radiation exposure, and the ability to perform minimally invasive procedures without elevating the risk of implant misplacement. Apart from the SpineAssist/ Renaissance system, the da Vinci is increasingly applied in individual cases or small case series. While the application of robot-aided surgery is thus a promising field of research and many different techniques are investigated, questions regarding the reimbursement and sociocultural acceptance of medical robots remain unsolved. Nevertheless, as the examples of cranial navigation or endoscopic abdominal surgery demonstrate, novel technologies like robot-aided spine surgery will eventually clear these hurdles and help surgeons to provide better-quality care for their patients.

\section{Disclosure}

The authors report no conflicts of interest in this work.

\section{References}

1. Esses SI, Sachs BL, Dreyzin V. Complications associated with the technique of pedicle screw fixation. A selected survey of ABS members. Spine (Phila Pa 1976). 1993;18(15):2231-2238.

2. Watkins RG, Gupta A. Cost-effectiveness of image-guided spine surgery. Open Orthop J. 2010;4:228-233.

3. Arand M, Hartwig E, Hebold D, Kinzl L, Gebhard F. [Precision analysis of navigation-assisted implanted thoracic and lumbar pedicled screws. A prospective clinical study]. Unfallchirurg. 2001;104(11):1076-1081. German.

4. Kantelhardt SR, Martinez R, Baerwinkel S, Burger R, Giese A, Rohde V. Perioperative course and accuracy of screw positioning in conventional, open robotic-guided and percutaneous robotic-guided, pedicle screw placement. Eur Spine J. Jun 2011;20(6):860-868.

5. Goodrich JT. History of spine surgery in the ancient and medieval worlds. Neurosurg Focus. 2004;16(1):E2.

6. Knoeller SM, Seifried C. Historical perspective: history of spinal surgery. Spine (Phila Pa 1976). 2000;25(21):2838-2843.

7. Enchev Y. Neuronavigation: geneology [sic], reality, and prospects. Neurosurg Focus. 2009;27(3):E11.

8. Roberts DW, Strohbehn JW, Hatch JF, Murray W, Kettenberger H. A frameless stereotaxic integration of computerized tomographic imaging and the operating microscope. J Neurosurgery. 1986;65(4): $545-549$

9. Gelalis ID, Paschos NK, Pakos EE, et al. Accuracy of pedicle screw placement: a systematic review of prospective in vivo studies comparing free hand, fluoroscopy guidance and navigation techniques. Eur Spine J. 2012;21(2):247-255.

10. Ringel F, Stoffel M, Stüer C, Meyer B. Minimally invasive transmuscular pedicle screw fixation of the thoracic and lumbar spine. Neurosurgery. 2006;59(4 Suppl 2):ONS361-ONS366.
11. Wiesner L, Kothe R, Schulitz KP, Rüther W. Clinical evaluation and computed tomography scan analysis of screw tracts after percutaneous insertion of pedicle screws in the lumbar spine. Spine (Phila Pa 1976). 2000;25(5):615-621.

12. Schizas C, Michel J, Kosmopoulos V, Theumann N. Computer tomography assessment of pedicle screw insertion in percutaneous posterior transpedicular stabilization. Eur Spine J. 2007;16(5):613-617.

13. von Jako R, Finn MA, Yonemura KS, et al. Minimally invasive percutaneous transpedicular screw fixation: increased accuracy and reduced radiation exposure by means of a novel electromagnetic navigation system. Acta Neurochir (Wien). 2011;153(3):589-596.

14. Barnett GH, Kormos DW, Steiner CP, Weisenberger J. Intraoperative localization using an armless, frameless stereotactic wand. Technical note. J Neurosurg. 1993;78(3):510-514.

15. Raabe A, Krishnan R, Wolff R, Hermann E, Zimmermann M, Seifert V. Laser surface scanning for patient registration in intracranial image-guided surgery. Neurosurgery. 2002;50(4):797-801; discussion 802-803.

16. Kantelhardt SR, Keric N, Giese A. Management of C2 fractures using Iso-C(3D) guidance: a single institution's experience. Acta Neurochir (Wien). 2012;154(10):1781-1787.

17. Holly LT. Image-guided spinal surgery. Int J Med Robot. 2006;2(1): 7-15.

18. Gebhard F, Weidner A, Liener UC, Stöckle U, Arand M. Navigation at the spine. Injury. 2004;35 Suppl 1:S-A35-S-A45.

19. Hüfner T, Gebhard F, Grützner PA, Messmer P, Stöckle U, Krettek C. Which navigation when? Injury. 2004;35 Suppl 1:S-A30-S-A34.

20. Holly LT, Foley KT. Intraoperative spinal navigation. Spine (Phila Pa 1976). 2003;28(Suppl 15):S54-S61.

21. Bydon M, Xu R, Amin AG, et al. Safety and efficacy of pedicle screw placement using intraoperative computed tomography: consecutive series of 1148 pedicle screws. J Neurosurg Spine. 2014:1-9.

22. Cleary K, Clifford M, Stoianovici D, Freedman M, Mun SK, Watson V. Technology improvements for image-guided and minimally invasive spine procedures. IEEE Trans Inf Technol Biomed. 2002;6(4):249-261.

23. Sonntag VK. Navigation and MRI during surgery: spine advances. World Neurosurg. 2012;78(1-2):76-77.

24. Laine T, Lund T, Ylikoski M, Lohikoski J, Schlenzka D. Accuracy of pedicle screw insertion with and without computer assistance: a randomised controlled clinical study in 100 consecutive patients. Eur Spine J. 2000;9(3):235-240.

25. Verma R, Krishan S, Haendlmayer K, Mohsen A. Functional outcome of computer-assisted spinal pedicle screw placement: a systematic review and meta-analysis of 23 studies including 5,992 pedicle screws. Eur Spine J. 2010;19(3):370-375.

26. Rajasekaran S, Kanna PR, Shetty AP. Safety of cervical pedicle screw insertion in children: a clinicoradiological evaluation of computer-assisted insertion of 51 cervical pedicle screws including 28 subaxial pedicle screws in 16 children. Spine (Phila Pa 1976). 2012;37(4):E216-E223.

27. Tian NF, Huang QS, Zhou P, et al. Pedicle screw insertion accuracy with different assisted methods: a systematic review and meta-analysis of comparative studies. Eur Spine J. 2011;20(6):846-859.

28. Mason A, Paulsen R, Babuska JM, et al. The accuracy of pedicle screw placement using intraoperative image guidance systems. J Neurosurg Spine. 2014;20(2):196-203.

29. Nakashima H, Sato K, Ando T, Inoh H, Nakamura H. Comparison of the percutaneous screw placement precision of isocentric C-arm 3-dimensional fluoroscopy-navigated pedicle screw implantation and conventional fluoroscopy method with minimally invasive surgery. J Spinal Disord Tech. 2009;22(7):468-472.

30. Villard J, Ryang YM, Demetriades AK, et al. Radiation exposure to the surgeon and the patient during posterior lumbar spinal instrumentation: a prospective randomized comparison of navigated versus non-navigated freehand techniques. Spine (Phila Pa 1976). 2014;39(13):1004-1009.

31. Lonstein JE, Denis F, Perra JH, Pinto MR, Smith MD, Winter RB Complications associated with pedicle screws. J Bone Joint Surg Am. 1999;81(11):1519-1528.

32. Härtl R, Lam KS, Wang J, Korge A, Kandziora F, Audigé L. Worldwide survey on the use of navigation in spine surgery. World Neurosurg. 2013;79(1):162-172. 
33. Devito DP, Kaplan L, Dietl R, et al. Clinical acceptance and accuracy assessment of spinal implants guided with SpineAssist surgical robot: retrospective study. Spine (Phila Pa 1976). 2010;35(24):2109-2115.

34. Schatlo B, Molliqaj G, Cuvinciuc V, Kotowski M, Schaller K, Tessitore E. Safety and accuracy of robot-assisted versus fluoroscopy-guided pedicle screw insertion for degenerative diseases of the lumbar spine: a matched cohort comparison. J Neurosurg Spine. 2014;20(6):636-643.

35. Shweikeh F, Amadio JP, Arnell M, et al. Robotics and the spine: a review of current and ongoing applications. Neurosurg Focus. 2014;36(3):E10.

36. Sutherland $\mathrm{G}$. Introduction to virtual reality and robotics in neurosurgery. Neurosurgery. 2013;72 Suppl 1:7.

37. Zhang C, Wang Z, Zhang C, Chen F, Zhang H, Yan X. Spine Bull's-Eye Robot guidewire placement with pedicle standard axis view for thoracic and lumbar pedicle screw fixation. J Spinal Disord Tech. 2012;25(7): E191-E198.

38. Kostrzewski S, Duff JM, Baur C, Olszewski M. Robotic system for cervical spine surgery. Int J Med Robot. 2012;8(2):184-190.

39. Kim S, Chung J, Yi BJ, Kim YS. An assistive image-guided surgical robot system using O-arm fluoroscopy for pedicle screw insertion: preliminary and cadaveric study. Neurosurgery. 2010;67(6):1757-1767; discussion 1767

40. Ortmaier T, Weiss H, Hagn U, et al. A hands-on-robot for accurate placement of pedicle screws. In: Proceedings 2006 IEEE International Conference on Robotics and Automation. Piscataway (NJ): Institute of Electrical and Electronics Engineers; 2006:4179-4186.

41. Lo SS, Chang EL, Yamada Y, Sloan AE, Suh JH, Mendel E. Stereotactic radiosurgery and radiation therapy for spinal tumors. Expert Rev Neurother. 2007;7(1):85-93.

42. Wang T, Luan S, Hu L, Liu Z, Li W, Jiang L. Force-based control of a compact spinal milling robot. Int J Med Robot. 2010;6(2):178-185.

43. Penzkofer T, Isfort P, Bruners P, et al. Robot arm based flat panel CTguided electromagnetic tracked spine interventions: phantom and animal model experiments. Eur Radiol. 2010;20(11):2656-2662.

44. Masamune K, Fichtinger G, Patriciu A, et al. System for robotically assisted percutaneous procedures with computed tomography guidance. Comput Aided Surg. 2001;6(6):370-383.

45. Kelly BP, Bennett CR. Design and validation of a novel Cartesian biomechanical testing system with coordinated 6DOF real-time load control: application to the lumbar spine (L1-S, L4-L5). J Biomech. 2013;46(11):1948-1954.

46. Schulze M, Hartensuer R, Gehweiler D, Hölscher U, Raschke MJ, Vordemvenne T. Evaluation of a robot-assisted testing system for multisegmental spine specimens. J Biomech. 2012;45(8):1457-1462.

47. Magagnin V, Bo I, Turiel M, Fornari M, Caiani EG, Porta A. Effects of robot-driven gait orthosis treadmill training on the autonomic response in rehabilitation-responsive stroke and cervical spondylotic myelopathy patients. Gait Posture. 2010;32(2):199-204.

48. Bertelsen A, Melo J, Sánchez E, Borro D. A review of surgical robots for spinal interventions. Int J Med Robot. 2013;9(4):407-422.

49. Shoham M, Lieberman IH, Benzel EC, et al. Robotic assisted spinal surgery - from concept to clinical practice. Comput Aided Surg. 2007;12(2):105-115.

50. Togawa D, Kayanja MM, Reinhardt MK, et al. Bone-mounted miniature robotic guidance for pedicle screw and translaminar facet screw placement: part 2 - Evaluation of system accuracy. Neurosurgery. 2007;60(2 Suppl 1):ONS129-ONS139.

Robotic Surgery: Research and Reviews

\section{Publish your work in this journal}

Robotic Surgery: Research and Reviews is an international, peer reviewed, open access, online journal publishing original research, commentaries, reports, and reviews on the theory, use and application of robotics in surgical interventions. Articles on the use of supervisory-controlled robotic systems, telesurgical devices, and shared-control systems are
51. Kantelhardt SR, Bock HC, Siam L, et al. Intra-osseous ultrasound for pedicle screw positioning in the subaxial cervical spine: an experimental study. Acta Neurochir (Wien). 2010;152(4):655-661.

52. Lieberman IH, Togawa D, Kayanja MM, et al. Bone-mounted miniature robotic guidance for pedicle screw and translaminar facet screw placement: Part I - Technical development and a test case result. Neurosurgery. 2006;59(3):641-650; discussion 641-650.

53. Barzilay Y, Liebergall M, Fridlander A, Knoller N. Miniature robotic guidance for spine surgery - introduction of a novel system and analysis of challenges encountered during the clinical development phase at two spine centres. Int J Med Robot. 2006;2(2):146-153.

54. Barzilay Y, Schroeder JE, Hiller N, et al. Robot-assisted vertebral body augmentation: a radiation reduction tool. Spine (Phila Pa 1976). 2014;39(2):153-157.

55. Kantelhardt SR, Keric N, Conrad J, et al. C-OnSite for intraoperative 3D control of pedicular screw positions. Acta Neurochir (Wien). 2014;156(9):1799-1805.

56. Hu X, Ohnmeiss DD, Lieberman IH. Robotic-assisted pedicle screw placement: lessons learned from the first 102 patients. Eur Spine J. 2013;22(3):661-666.

57. Roser F, Tatagiba M, Maier G. Spinal robotics: current applications and future perspectives. Neurosurgery. 2013;72 Suppl 1:12-18.

58. Pechlivanis I, Kiriyanthan G, Engelhardt M, et al. Percutaneous placement of pedicle screws in the lumbar spine using a bone mounted miniature robotic system: first experiences and accuracy of screw placement. Spine (Phila Pa 1976). 2009;34(4):392-398.

59. Schizas C, Thein E, Kwiatkowski B, Kulik G. Pedicle screw insertion: robotic assistance versus conventional C-arm fluoroscopy. Acta Orthop Belg. 2012;78(2):240-245

60. Ringel F, Stüer C, Reinke A, et al. Accuracy of robot-assisted placement of lumbar and sacral pedicle screws: a prospective randomized comparison to conventional freehand screw implantation. Spine (Phila Pa 1976). 2012;37(8):E496-E501.

61. Yang MS, Yoon DH, Kim KN, et al. Robot-assisted anterior lumbar interbody fusion in a swine model in vivo test of the da Vinci surgicalassisted spinal surgery system. Spine (Phila Pa 1976). 2011;36(2): E139-E143.

62. Lee JY, Bhowmick DA, Eun DD, Welch WC. Minimally invasive, robot-assisted, anterior lumbar interbody fusion: a technical note. J Neurol Surg A Cent Eur Neurosurg. 2013;74(4):258-261.

63. Yang MS, Kim KN, Yoon DH, Pennant W, Ha Y. Robot-assisted resection of paraspinal schwannoma. J Korean Med Sci. 2011;26(1):150-153.

64. Perez-Cruet MJ, Welsh RJ, Hussain NS, Begun EM, Lin J, Park P. Use of the da Vinci minimally invasive robotic system for resection of a complicated paraspinal schwannoma with thoracic extension: case report. Neurosurgery. 2012;71(Suppl Operative 1):209-214.

65. Lee JY, Lega B, Bhowmick D, et al. da Vinci robot-assisted transoral odontoidectomy for basilar invagination. ORL J Otorhinolaryngol Relat Spec. 2010;72(2):91-95.

66. Lee JY, O’Malley BW, Newman JG, et al. Transoral robotic surgery of craniocervical junction and atlantoaxial spine: a cadaveric study. J Neurosurg Spine. 2010;12(1):13-18.

67. Sukovich W, Brink-Danan S, Hardenbrook M. Miniature robotic guidance for pedicle screw placement in posterior spinal fusion: early clinical experience with the SpineAssist. Int J Med Robot. 2006;2(2):114-122.

invited. The manuscript management system is completely online and includes a very quick and fair peer review system, which is all easy to use. Visit http://www.dovepress.com/testimonials.php to read real quotes from published authors. 